\title{
Serodiagnosis of Infectious Mononucleosis by Using Recombinant Epstein-Barr Virus Antigens and Enzyme-Linked Immunosorbent Assay Technology
}

\author{
MERI GORGIEVSKI-HRISOHO, ${ }^{1}$ WALTER HINDERER, ${ }^{2}$ HEIKE NEBEL-SCHICKEL,${ }^{2}$ JÜRGEN HORN, ${ }^{2}$ \\ ROLF VORNHAGEN, ${ }^{2}$ HANS-H. SONNEBORN, ${ }^{2}$ HANS WOLF, ${ }^{3}$ AND GÜNTER SIEGL ${ }^{1}{ }^{*}$ \\ Division of Virology, Institute for Medical Microbiology, University of Bern, Bern, Switzerland, ${ }^{1}$ and Research and \\ Development, Biotest AG, Offenbach, ${ }^{2}$ and Max von Pettenkofer Institute for Hygiene and Medical Microbiology, \\ University of Munich, Munich, ${ }^{3}$ Federal Republic of Germany
}

Received 22 January 1990/Accepted 11 July 1990

\begin{abstract}
Four recombinant, diagnostically useful Epstein-Barr virus (EBV) proteins representative of the viral capsid antigen (p150), diffuse early antigen (p54), the major DNA-binding protein (p138), and the EBV nuclear antigen (p72) (W. Hinderer, H. Nebel-Schickel, H. H. Sonneborn, M. Motz, R. Kühbeck, and H. Wolf, J. Exp. Clin. Cancer Res. 7[Suppl.]:132, 1988) were used to set up individual enzyme-linked immunosorbent assays (ELISAs) for the qualitative and quantitative detection of immunoglobulin M (IgM) and IgG antibodies. In direct comparison with results obtained by standard immunofluorescence or immunoperoxidase assays, it was then shown that the recombinant EBV ELISAs provide the means for specific and sensitive serodiagnosis of infectious mononucleosis (IM) caused by EBV. The most useful markers in sera from such patients proved to be IgM antibodies against p54, p138, and p150. Additional positive markers for recent or ongoing IM apparently were IgG antibodies against p54 and p138. In contrast, anti-p72 IgG had a high preference for sera from healthy blood donors and, therefore, can be considered indicative of past exposure to the virus. Altogether, the individual ELISAs proved to be as specific and at least as sensitive for the diagnosis of IM as the currently available standard techniques are. Moreover, our findings suggest that, by combining individual test antigens, a workable ELISA system consisting of three assays (IgM against p54, p138, and p150; IgG against p54 and p138; and IgG against p72) can be established for the standardized rapid diagnosis of acute EBV infections.
\end{abstract}

The syndrome infectious mononucleosis (IM) comprises mainly fever, pharingitis, and cervical lymphadenopathy but may be complicated by splenomegaly, hepatitis, and myalgia, as well as headache and further unspecific symptoms (2). The causative agent of IM is Epstein-Barr Virus (EBV); however, other pathogens, mainly cytomegalovirus but also adenovirus, rubella virus, human immunodeficiency virus, and Toxoplasma gondii, can cause a similar syndrome. At present, testing for heterophil antibodies is frequently used to relate IM to EBV infection. These so-called Paul-Bunnell tests are simple and rapid; yet, the test results are not necessarily conclusive, because heterophil antibodies can also be induced by viruses other than EBV and because their incidence among patients with IM is, at most, $90 \%$ (3). In particular, young children ( $<4$ years old) often lack a heterophil antibody response (22).

The uncertainties of the Paul-Bunnell reaction can be overcome by specific EBV serodiagnosis (10). To date this is predominantly performed by indirect immunofluorescence (IF) or immunoperoxidase (IP) staining of EBV-infected cells. Standard assays make use of fixed cells derived from selected EBV-infected cell cultures which specifically express EBV-associated antigens such as the viral capsid antigens (VCAs), a set of early antigens (EAs, which can be subdivided into EA diffuse and EA restricted), and EBV nuclear antigens (EBNAs); these antigens correspond to the late lytic phase, the early lytic phase, and the phase of

\footnotetext{
* Corresponding author.

† Present address: Institute for Clinical Microbiology and Immunology, Frohbergstrasse 3, CH-9000 St. Gallen, Switzerland.
}

latency of EBV infections, respectively. Qualitative and quantitative determinations of immunoglobulin $\mathbf{M}$ (IgM) and/or IgG antibodies against individual antigens or combinations of these antigens then allows discrimination among primary, past, and reactivated EBV infections. However, IF assays are time-consuming and are not suitable for largescale testing, and because of variability of antigen-producing cells as well as subjective reading of results, they are also difficult to standardize.

Various attempts have been made to facilitate the specific serodiagnosis of EBV infections by developing microdilution plate assays based either on native antigens purified from EBV-infected cells (19) or on synthetic peptides selected empirically or by computer analysis from the amino acid sequences of presumptively relevant EBV-associated antigens $(4,5,16)$. The complexity of the phase-specific antigens, as well as the lack of suitable culture systems for bulk production, however, do not support their use for routine diagnosis.

By using recombinant DNA technology, defined EBVspecific antigens can be produced in sufficient amounts. Recently, suitable EBV polypeptides were selected by computer-assisted predictions of putative immunogenic regions as well as by immunoprecipitation and Western immunoblot experiments with defined EBV sera $(18,24)$. The antigens were cloned, expressed in Escherichia coli, and purified to apparent homogeneity (11). These recombinant proteins showed excellent reactivities when they were included in Western blots or enzyme-linked immunosorbent assays (ELISAs) in preliminary diagnostic studies. They have now been used to set up ELISAs for the diagnosis of EBV- 
associated diseases. In this study we showed that, in direct comparison with results obtained by standard IF assays, these recombinant EBV ELISAs provide the means for the specific, sensitive, and rapid serodiagnosis of IM or, in more general terms, of the early acute phase of EBV infection.

\section{MATERIALS AND METHODS}

Sera. A total of 75 serum specimens were collected from 57 patients who presented with clinical symptoms suggestive of IM. The symptoms commonly found in these patients included fever, tonsillar enlargement, lymphadenopathy, splenomegaly and/or hepatomegaly, hepatitis, rash, and atypical blood lymphocytes. Two to four follow-up serum specimens were available from 13 of the patients. Age, sex, and the time at which the samples were collected are specified in Tables 2 and 3. In addition, 161 serum specimens were obtained from asymptomatic, healthy blood donors (ABDs).

Standard laboratory diagnosis. Serologic diagnosis of acute EBV infection was performed by the standard methods $(10,20)$ routinely used in our laboratory. IgG antibodies to VCA and EA were determined by indirect IF on the basis of slides prepared from antigen-producing P3HR1 cells in our laboratory and by use of slides purchased from Gull Laboratories, Inc. (Salt Lake City, Utah), respectively. IgM antibodies to VCA were assayed by indirect IP staining on slides available from Savyon Diagnostics Ltd. (Beer Sheva, Israel). To remove unspecific reactivities as a result of the presence of rheumatoid factors and antigen-specific IgG, the sera were preadsorbed as specified by the manufacturer of the test system. Finally, antibodies against EBNA were determined by anticomplement IF (ACIF) on slides purchased from Gull Laboratories. Sera from patients with a presumptive clinical diagnosis of IM were initially tested for IgM antibodies to VCA (VAC-IgM). If the result was negative or inconclusive, a second serum specimen was requested. For the positive diagnosis of acute EBV infection, suggestive clinical symptoms must be matched by serologic parameters indicative of a current or recent acute EBV infection. These parameters consisted of a combination of the presence of VCA-IgM, the absence or presence at very low titers of antibodies to EBNA only, or the presence of IgG antibodies to VCA (VCA-IgG) and IgG antibodies to EA.

Recombinant EBV antigens. The selected EBV genomic regions were cloned and expressed in $E$. coli JM109 by using standard pUC vectors. All four clones expressed stable proteins without fused bacterial proteins (see Table 1). The recombinant antigens were produced at a preparative scale in $\mathrm{L}$ broth starting with a culture volume of 6 liters and inducing synthesis by treatment with $1 \mathrm{mM}$ isopropyl- $\beta-D-$ thiogalactopyranoside over a period of $4 \mathrm{~h}$. Cells were harvested by centrifugation; after lysis of cells with lysozyme and subsequent sonification, the antigens were purified either from the supernatant (for p54 and p72) or from the insoluble sediment (for p138 and p150). Purification of soluble proteins consisted of fractionation with ammonium sulphate, ion-exchange chromatography, and a final gel chromatography. The insoluble protein aggregates (inclusion bodies) of p138 and p150 were purified by differential washing and centrifugation with increasing concentrations of detergents and chaotropic reagents at different $\mathrm{pH}$ values. The average yields of the apparently homogeneous antigens ranged from $8 \mathrm{mg}$ (p72) to $240 \mathrm{mg}$ (p138) per preparation. Purification was monitored by sodium dodecyl sulfate
(SDS)-polyacrylamide gel electrophoresis and followed by Coomassie staining or by Western blotting under standard conditions. For Western blotting, well-defined sera were used, i.e., those that were either negative or positive for the individual EBV-associated antigen, a serum specimen that recognized $E$. coli proteins, as well as two monoclonal antibodies directed against p54 and p138. The final purity of the recombinant polypeptides, as calculated from gels and blots, was near $100 \%$, except for p150, which was obtained at about $95 \%$ purity.

Western blots. Proteins were separated by discontinuous gel electrophoresis by the method of Laemmli (13) and transferred onto membranes (Immobilon; Millipore Corp., Bedford, Mass.) by using a semidry blotting technique (12). The blocking solution contained $10 \mathrm{mg}$ of bovine serum albumin per $\mathrm{ml}$ in phosphate-buffered saline. Blots were cut into strips $(5 \mathrm{~mm})$, each of which was incubated in $2.5 \mathrm{ml}$ of serum diluted 1:50 in phosphate-buffered saline with $1 \mathrm{mg}$ of bovine serum albumin per $\mathrm{ml}$ for $4 \mathrm{~h}$ at room temperature. This was followed by washing (four times) with $5 \mathrm{ml}$ of phosphate-buffered saline supplemented with $0.1 \%$ Tween 80. Polyclonal rabbit anti-human IgG or IgM conjugated with horseradish peroxidase (Dako, Glostrup, Denmark) was used as revealing antibody $(1.5 \mathrm{~h}$, room temperature). Staining of strips was performed with 3,3'-diaminobenzidine. Sera from blood donors which were ELISA positive were retested by this Western blot method by using strips with 100 ng of the corresponding purified antigen. The appearance of antigen-specific bands was defined as confirmation of an antigen-specific ELISA reaction.

ELISA procedure. Polystyrene microdilution plates (96well; Nunc) were coated with the purified antigens at the concentrations specified in Table 1 . Identical plates were used for IgG and IgM testing. Murine monoclonal antibodies, anti-human IgG (Biotest AG, Offenbach, Federal Republic of Germany) and anti-human IgM (Janssen, Beerse, Belgium), both of which were conjugated with horseradish peroxidase, served as second antibodies. Sera were diluted 1:21 and allowed to react with the antigens at $40^{\circ} \mathrm{C}$ for either 30 (IgG) or 60 (IgM) min. This was followed by incubation with the second antibody at $40^{\circ} \mathrm{C}$ for $30 \mathrm{~min}$ and reaction with the substrate (1,2-phenylenediamine) at room temperature for $15 \mathrm{~min}$. All reagents were used in standard volumes of $100 \mu \mathrm{l}$. The optical densities (ODs) at 492 and $620 \mathrm{~nm}$ were measured. Sera were always assayed in duplicate; and blank, negative, as well as positive control sera were included on each plate.

To avoid false-positive results in the IgM determinations because of the presence of rheumatoid factors (8), sera were treated overnight at 2 to $8^{\circ} \mathrm{C}$ with a polyclonal goat antihuman IgG Fc serum.

Frequencies of antibodies in sera from patients with IM. For calculation of the positive rates of the recombinant ELISAs, only VCA-IgM-positive sera were used, i.e., the serum specimens described in Table 2 , with the exception of the serum specimen from patient 2 , together with the first VCA-IgM-positive serum specimens from the serial samples listed in Table 3. The total number of serum specimens included was 33 .

\section{RESULTS}

Cutoff values of ELISAs. Serum specimens from 34 patients with a presumptive clinical and confirmed laboratory diagnosis of IM as well as serum specimens from 161 healthy blood donors were used to analyze the reactivities of the 
TABLE 1. Characteristics of recombinant EBV antigens used in this study

\begin{tabular}{llllcc}
\hline Antigen & Reading frame & \multicolumn{1}{c}{ Classification } & \multicolumn{1}{c}{ Construction } & $\begin{array}{c}\text { Size }\left(M_{\mathrm{r}}[\mathrm{kilodaltons})\right. \\
\text { of expressed protein }\end{array}$ & $\begin{array}{c}\text { Concn }(\mu \mathrm{g} / \mathrm{ml}) \text { in } \\
\text { coating solution }\end{array}$ \\
\hline p54 & BMRF1 & EA (diffuse) & Whole coding region & 52,47 & 1 \\
p138 & BALF2 & EA (major DNA-binding protein) & Fusion of two selected sections & 39 & 1 \\
p150 & BcLF1 & VCA & Fusion of two selected sections & 47,22 & 10 \\
p72 & BKRF1 & Nuclear antigen (EBNA-1) & C-terminal part (42.7\%) & 46 & 0.25 \\
\hline
\end{tabular}

four recombinant EBV antigens by a diagnostic ELISA. Thereby, individual antigens were used for coating microdilution plates in concentrations determined earlier (11) and as specified in Table 1 . The cutoff values were set at ODn + 0.1 , where ODn is the OD recorded by use of a control human serum which proved to be negative for antibodies against all EBV-associated antigens in standard IF tests as well as against the recombinant antigens in Western blots. The ODs of this serum specimen varied from 0.000 to 0.051 for IgG assays and from 0.001 to 0.116 for IgM assays with the four antigens in different series of experiments. Sera that were reactive in the range of an OD cutoff of \pm 0.05 were considered equivocal.

Significance of IgM antibodies. Concerning the frequency and diagnostic significance of antibodies against individual antigens (markers), the data in Tables 2 and 3 indicate that marker combinations as well as relative intensities differed considerably among patients. The most sensitive marker, which was present in sera from all but one patient and which gave rise to high ODs in most cases, was anti-p138-IgM. This was followed by anti-p54-IgM, which was negative in sera from only three patients. The prevalence, and, hence, the diagnostic significance of the IgM antibodies that react with the recombinant p150 protein, was considerably lower. In one case (patient 5), however, from whose serum all other markers were absent, anti-p150-IgM proved to be indicative for primary EBV infection. Finally, anti-p72-IgM evidently failed to contribute substantially to the diagnosis of IM.

Significance of IgG antibodies. The diagnostic significance of IgG antibodies against the different recombinant proteins coincided with that of IgM antibodies (Tables 2 and 3). Anti-p138-IgG and anti-p54-IgG were highly prevalent, and at least one of these markers was present in serum specimens from 32 of 34 patients. In contrast, the incidence of anti-p150-IgG was low and anti-p72-IgG was absent in $\mathbf{3 0}$ of 34 serum specimens from patients with confirmed IM. The

TABLE 2. Comparison of EBV serological parameters determined by standard techniques and recombinant ELISAs in sera from 25 patients with confirmed recent or acute EBV infection

\begin{tabular}{|c|c|c|c|c|c|c|c|c|c|c|c|c|c|c|c|}
\hline \multirow{3}{*}{$\begin{array}{c}\text { Patient } \\
\text { no. }\end{array}$} & \multirow{3}{*}{ Age (yr) } & \multirow{3}{*}{$\operatorname{Sex}^{a}$} & \multicolumn{4}{|c|}{ IF $^{b}$} & \multicolumn{8}{|c|}{ ELISA OD $^{c}$} & \multirow{3}{*}{$\mathbf{R}^{d}$} \\
\hline & & & \multirow{2}{*}{$\begin{array}{l}\text { VCA- } \\
\text { IgG }\end{array}$} & \multirow{2}{*}{$\begin{array}{l}\text { VCA- } \\
\text { IgM }\end{array}$} & \multirow{2}{*}{$\begin{array}{c}\text { EBNA- } \\
\text { Ig }\end{array}$} & \multirow{2}{*}{$\begin{array}{l}\text { EA- } \\
\text { IgG }\end{array}$} & \multicolumn{2}{|c|}{ p54 } & \multicolumn{2}{|c|}{ p138 } & \multicolumn{2}{|c|}{$\mathrm{p} 150$} & \multicolumn{2}{|c|}{ p72 } & \\
\hline & & & & & & & IgG & $\operatorname{IgM}$ & IgG & IgM & IgG & IgM & IgG & IgM & \\
\hline 1 & 2 & $\mathbf{M}$ & $<10$ & + & - & 10 & - & - & ++ & - & + & - & - & - & + \\
\hline 2 & 2 & $\mathbf{F}$ & $<10$ & \pm & - & $>40$ & - & \pm & ++ & \pm & + & - & - & - & + \\
\hline 3 & 2 & $\mathbf{M}$ & $<10$ & + & - & 10 & + & + & - & + & - & + & - & - & + \\
\hline 4 & 5 & $\mathbf{F}$ & 640 & + & - & $>160$ & + & + & + & + & + & + & - & - & + \\
\hline 5 & 6 & $\mathbf{M}$ & 160 & + & - & $<10$ & - & - & - & \pm & - & + & - & - & + \\
\hline 6 & 9 & $\mathbf{F}$ & 40 & + & - & 640 & + & ++ & + & + & - & - & - & \pm & + \\
\hline 7 & 10 & $\mathbf{M}$ & 160 & + & - & 640 & - & + & + & + & \pm & + & - & + & + \\
\hline 8 & 11 & $\mathbf{M}$ & 160 & + & - & 40 & - & - & ++ & +++ & - & + & - & - & + \\
\hline 9 & 14 & $\mathbf{F}$ & 640 & + & - & 160 & + & + & + & + & - & \pm & - & - & + \\
\hline 10 & 15 & $\mathbf{F}$ & 160 & + & - & 160 & + & +++ & + & +++ & - & + & - & - & + \\
\hline 11 & 15 & $\mathbf{F}$ & 10 & + & - & 10 & + & + & \pm & + & - & \pm & - & \pm & + \\
\hline 12 & 16 & $\mathbf{F}$ & 160 & + & - & 40 & + & + & \pm & +++ & - & \pm & - & \pm & + \\
\hline 13 & 16 & $\mathbf{M}$ & 160 & + & - & $>40$ & \pm & \pm & + & + & + & - & - & + & + \\
\hline 14 & 18 & $\mathbf{M}$ & 160 & + & - & 80 & ++ & ++ & + & + & + & + & - & \pm & + \\
\hline 15 & 19 & $\mathbf{M}$ & 40 & + & - & 10 & - & + & + & ++ & \pm & + & - & - & + \\
\hline 16 & 20 & $\mathbf{F}$ & 160 & + & - & 40 & + & + & + & ++ & \pm & + & - & - & + \\
\hline 17 & 21 & $\mathbf{M}$ & 160 & + & - & 10 & - & \pm & - & \pm & - & - & - & - & - \\
\hline 18 & 21 & $\mathbf{M}$ & 640 & + & - & 10 & + & ++ & + & + & \pm & + & - & - & + \\
\hline 10 & 21 & $\mathbf{M}$ & 160 & + & - & 40 & + & + & + & +++ & \pm & + & - & \pm & + \\
\hline 20 & 21 & $\mathbf{M}$ & 40 & + & - & 40 & ++ & + & +++ & +++ & \pm & + & - & + & + \\
\hline 21 & 21 & $\mathbf{M}$ & 160 & + & - & 10 & \pm & + & \pm & +++ & ++ & + & - & \pm & + \\
\hline 22 & 22 & $\mathbf{M}$ & 160 & + & - & 40 & + & +++ & +++ & ++ & \pm & + & - & + & + \\
\hline 23 & 24 & $\mathbf{M}$ & 40 & + & \pm & 160 & \pm & + & + & +++ & + & - & ++ & - & $+{ }^{e}$ \\
\hline 24 & 27 & $\mathbf{M}$ & 160 & + & - & 40 & + & +++ & + & +++ & + & + & \pm & + & + \\
\hline 25 & 32 & $\mathbf{F}$ & 160 & + & - & 40 & +++ & +++ & +++ & +++ & \pm & \pm & - & - & + \\
\hline
\end{tabular}

${ }^{a} \mathbf{M}$, Male; F, female.

${ }^{b}$ Interpretation of standard IF results: VCA-IgG, IgG antibodies against viral capsid antigen (positive, $\geq 1: 10$ );VCA-IgM, IgM antibodies against VCA (positive, $\geq 1: 64$; \pm , 1:32); EBNA-Ig, antibodies against EBNA (positive, $>1: 10$; \pm weak fluorescence, 1:10); EA-IgG, IgG antibodies to EA (positive, $\geq 1: 10$ ).

${ }^{c}$ Interpretation of ELISA results:,$- \mathrm{OD}<\mathrm{OD}$ cutoff $-0.05 ; \pm, \mathrm{OD}=\mathrm{OD}$ cutoff $\pm 0.05 ;+, \mathrm{OD}>\mathrm{OD}$ cutoff +0.05 to $1.0 ;++, \mathrm{OD}=1.00$ to $2.00 ;+++$, OD $>2.00$.

${ }^{d}$ R, Laboratory diagnosis according to ELISA results: +, acute EBV infection; -, no evidence for acute EBV infection.

e Possible reactivation. 
TABLE 3. Time course of serological parameters in patients with confirmed acute infection as determined by current standard diagnostic technique and recombinant ELISA

\begin{tabular}{|c|c|c|c|c|c|c|c|c|c|c|c|c|c|c|c|}
\hline \multirow{3}{*}{$\begin{array}{l}\text { Patient and } \\
\text { serum } \\
\text { sample }\end{array}$} & \multirow{3}{*}{$\begin{array}{l}\text { Age } \\
\text { (yr) }\end{array}$} & \multirow{3}{*}{$\operatorname{Sex}^{a}$} & \multirow{3}{*}{$\begin{array}{c}\text { Date } \\
\text { (day.mo.yr) }\end{array}$} & \multicolumn{4}{|c|}{$\mathrm{IF}^{b}$} & \multicolumn{8}{|c|}{ ELISA OD $^{c}$} \\
\hline & & & & \multirow{2}{*}{$\begin{array}{l}\text { VCA- } \\
\text { IgG }\end{array}$} & \multirow{2}{*}{$\begin{array}{l}\text { VCA- } \\
\text { IgM }\end{array}$} & \multirow{2}{*}{$\underset{\text { Ig }}{\text { EBNA- }}$} & \multirow{2}{*}{$\begin{array}{l}\text { EA- } \\
\text { IgG }\end{array}$} & \multicolumn{2}{|c|}{ p54 } & \multicolumn{2}{|c|}{ p138 } & \multicolumn{2}{|c|}{$\mathrm{p} 150$} & \multicolumn{2}{|c|}{ p72 } \\
\hline & & & & & & & & IgG & IgM & IgG & IgM & IgG & IgM & IgG & IgM \\
\hline \multicolumn{16}{|l|}{26} \\
\hline 1 & 4 & F & 4.5 .88 & 160 & - & - & $<10$ & 0.008 & 0.005 & 0.038 & 0.053 & 0.149 & 0.003 & 0.003 & 0.008 \\
\hline 2 & 4 & $\mathrm{~F}$ & 5.5 .88 & 160 & + & _- & $<10$ & 0.028 & 0.029 & 0.109 & 0.387 & 0.404 & 0.045 & 0.013 & 0.054 \\
\hline 3 & 4 & $\mathrm{~F}$ & 14.5 .88 & 1,280 & + & - & 160 & 0.340 & 0.148 & 0.815 & 0.145 & 0.360 & 0.105 & 0.164 & 0.040 \\
\hline 4 & 4 & $\mathrm{~F}$ & 27.5.88 & 1,280 & + & - & $>160$ & 0.458 & 0.131 & 0.548 & 0.074 & 0.227 & 0.088 & 0.086 & 0.040 \\
\hline \multicolumn{16}{|l|}{27} \\
\hline 1 & 6 & F & 30.8 .88 & 160 & + & - & 40 & 0.032 & 0.265 & 0.214 & 0.353 & 0.132 & 0.507 & 2.588 & 0.177 \\
\hline 2 & 6 & F & 17.10 .88 & 160 & + & + & 40 & 0.024 & 0.208 & 0.189 & 0.234 & 0.116 & 0.388 & 2.617 & 0.127 \\
\hline \multicolumn{16}{|l|}{28} \\
\hline 1 & 13 & F & 10.3 .89 & 160 & \pm & - & 10 & 2.889 & 0.167 & 2.488 & 2.383 & 0.269 & 0.110 & 0.004 & 0.214 \\
\hline 2 & 13 & $\mathbf{F}$ & 16.3 .89 & 640 & + & - & 40 & 2.645 & 0.200 & 2.058 & 1.445 & 0.213 & 0.122 & 0.009 & 0.072 \\
\hline 3 & 13 & $\mathrm{~F}$ & 3.4 .89 & 640 & \pm & - & 40 & 2.442 & 0.116 & 0.767 & 0.737 & 0.200 & 0.095 & 0.005 & 0.144 \\
\hline \multicolumn{16}{|l|}{29} \\
\hline 1 & 12 & F & 15.3 .88 & $<10$ & \pm & - & $<10$ & 0.040 & 0.212 & 0.533 & 0.947 & 0.148 & 0.194 & 0.023 & 0.296 \\
\hline 2 & 12 & $\mathbf{F}$ & 25.11 .88 & 40 & + & - & $<10$ & 0.059 & 0.625 & 1.085 & 1.008 & 0.193 & 0.178 & 0.031 & 0.361 \\
\hline 3 & 12 & F & 5.12 .88 & 160 & + & - & 40 & 0.304 & 1.836 & 1.837 & 1.676 & 0.155 & 0.252 & 0.023 & 0.131 \\
\hline \multicolumn{16}{|l|}{30} \\
\hline 1 & 15 & $\mathbf{M}$ & 25.8 .88 & 160 & + & - & $<10$ & 0.678 & 0.047 & 0.107 & 0.078 & 0.064 & 0.052 & 1.740 & 0.039 \\
\hline 2 & 15 & $\mathbf{M}$ & 12.9 .88 & 160 & + & \pm & 40 & 0.300 & 0.382 & 0.100 & 0.144 & 0.048 & 0.175 & 1.633 & 0.143 \\
\hline \multicolumn{16}{|l|}{31} \\
\hline 1 & 22 & $\mathbf{F}$ & 24.5 .88 & $<10$ & \pm & - & $<10$ & 0.028 & 0.049 & 0.153 & 0.086 & 0.144 & 0.069 & 0.114 & 0.085 \\
\hline 2 & 22 & F & 1.6 .88 & 160 & + & - & 40 & 0.361 & 0.783 & 0.714 & 0.884 & 0.118 & 0.111 & 0.009 & 0.009 \\
\hline \multicolumn{16}{|l|}{32} \\
\hline 1 & 25 & F & 10.5 .88 & 160 & + & - & 10 & 0.380 & 0.452 & 1.032 & 0.805 & 0.273 & 0.189 & 0.000 & 0.091 \\
\hline 2 & 25 & $\mathbf{F}$ & 30.8 .88 & 160 & \pm & \pm & 40 & 0.051 & 0.102 & 0.129 & 0.179 & 0.191 & 0.071 & 0.249 & 0.051 \\
\hline 3 & 25 & F & 17.2.89 & 160 & - & + & 40 & 0.032 & 0.050 & 0.085 & 0.193 & 0.160 & 0.081 & 2.179 & 0.049 \\
\hline \multicolumn{16}{|l|}{33} \\
\hline 1 & 25 & F & 16.3 .88 & 40 & + & - & 40 & 0.042 & 0.517 & 0.468 & 0.915 & 0.189 & 0.152 & 0.039 & 0.094 \\
\hline 2 & 25 & F & 18.3 .88 & 160 & + & - & 10 & 0.146 & 0.283 & 1.008 & 1.227 & 0.146 & 0.183 & 0.076 & 0.158 \\
\hline \multicolumn{16}{|l|}{34} \\
\hline 1 & 26 & $\mathbf{M}$ & 26.5 .88 & $<10$ & - & - & $<10$ & 0.058 & 0.518 & 0.370 & 0.275 & 0.394 & 0.058 & 0.042 & 0.020 \\
\hline 2 & 26 & $\mathbf{M}$ & 3.6.88 & 640 & + & - & 80 & 1.406 & 2.118 & 1.208 & 2.475 & 0.460 & 0.240 & 0.049 & 0.036 \\
\hline
\end{tabular}

${ }^{a} \mathrm{~F}$, Female; M, male.

${ }^{b}$ See footnote $b$ of Table 2 for explanations.

$c$ OD at 492 and $620 \mathrm{~nm}$ by ELISA. See footnote $c$ of Table 2 for explanations.

latter finding correlates excellently with the results of the standard ACIF test for EBNA (Tables 2 and 3). Exceptions were four patients, for whom EBNA ACIF values were either weakly positive (patients 23 and 30 ) or showed seroconversion in EBNA ACIF (patients 27 and 32). In sera from these patients, the p72-IgG ELISA was already positive in the first serum sample and, hence, proved to be of increased sensitivity.

Follow-up studies and seroconversion. The specificity and diagnostic significance of IgM and IgG antibodies against individual markers were underlined by their dynamic variation with the time of infection, as was evident for those patients from whom multiple serum specimens were available (Table 3). The panel of serum specimens from patient 32 represents an excellent example of such a course. It shows, in full agreement with IF and IP staining results, seroconversion to anti-p72-IgG in parallel with declining IgM antibodies to the other antigens. Moreover, the initial serum samples from five of nine patients with follow-up panels (Table 3) were not yet positive by IP staining of VCA-IgM. Three of these serum samples, however (those from patients 28,29 , and 34 ), were clearly IgM positive with the recombinant antigens.

Comparative reactivity in sera from patients with IM and ABDs. The reactivities of the recombinant antigens with sera from a control group of 161 apparently healthy blood donors was also investigated. All positive ELISA readings were confirmed by Western blotting. Figure 1 compares the prevalence of IgM and IgG antibodies to the four recombinant EBV-encoded antigens in sera from ABDs with those in sera from the 33 patients with confirmed IM. With the exception of low ODs against p138 in only $8 \%$ of the samples, no significant IgM reactivities with the recombinant antigens were detected in the sera from ABDs. On the contrary, most sera from patients with IM contained IgM antibodies to p54, p138, and p150 (see above). IgG antibodies to p54 and p138 

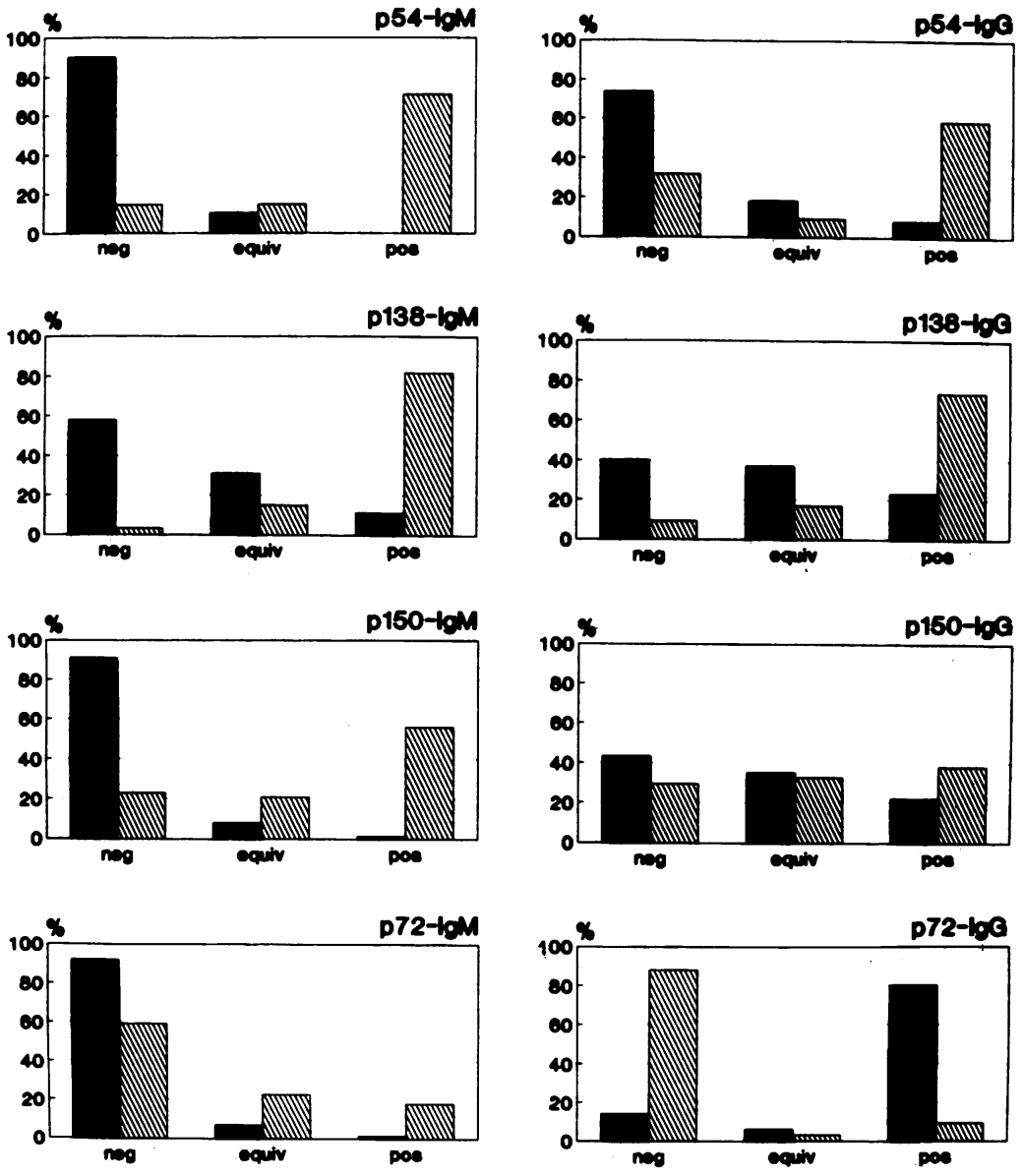

FIG. 1. Prevalence of IgG and IgM antibodies directed against different recombinant EBV antigens in sera from ABDs $(\square)(n=161)$ and patients with acute, serologically confirmed EBV infection $(\$)(n=33)$. Negative (neg), OD < OD cutoff - 0.05; equivalent (equiv), OD $=\mathrm{OD}$ cutoff $\pm 0.05 ;$ positive (pos), OD $>$ OD cutoff +0.05

were also strongly increased in sera from patients with IM. The incidence of anti-p150-IgG, however, was low and quite similar in sera from both patients with IM and ABDs. Finally, anti-p72-IgG seemed to be a useful marker for a past EBV infection, as $84 \%$ of sera from ABDs but only $9 \%$ of sera from patients with acute IM turned out to be positive for this marker. The mean absorption values in sera from ABDs were as follows: p72-IgG, 1.324; p54-, p138-, and p150-IgG, 0.129 to 0.169 ; p72-, p54-, p138-, and p150-IgM, 0.016 to 0.103 .

Reactivities of sera from patients with IM negative by VCA-IgM-IP. We tested 27 serum specimens from 23 patients who presented with IM-like symptoms, but these were found to be negative for anti-VCA-IgM by standard methods (data not shown in detail). Although they were requested, second serum specimens were available for only four patients, and these sera still proved to be negative for antiVCA-IgM. This was also confirmed by recombinant ELISA. On the other hand, 3 of the remaining 19 patients were found by ELISA to have acute EBV infections. This diagnosis could subsequently be supported by additional extended IF assays (negative anti-EBNA and positive anti-VCA-IgG for all three patients and positive anti-EA antibodies for two patients).

\section{DISCUSSION}

The antigen complexes VCA, EA, and EBNA which form the basis of the classical IF and IP staining assays for specific laboratory diagnosis of acute EBV infections are not well defined at the protein level. Despite this situation, the recombinant proteins used in the present study were selected to match these groups of antigens as much as possible. They do not necessarily represent, however, the predominant components of the VCA, EA, and EBNA antigen complexes. This was certainly true for the EA p138 (reading frame BALF2, major DNA-binding protein). This antigen is not expressed in chemically induced Raji cells (1), which are often used for EBV. EA assays, but is present in significant amounts in Raji cells superinfected with EBV from $\mathbf{P}_{\mathbf{3}} \mathbf{H R}_{\mathbf{1}}$ cells (10). Hence, the immunologic response to p138 does not contribute to anti-EA readings in some IF assays. According to the results of the present study, however, antibodies to a recombinant, truncated version of p138 (18) form a powerful marker for acute EBV infection.

The classical EA complex consists of two components: diffuse (EA-D) and restricted (EA-R). Of these, the EA-R component BORF2 (p85) is part of a ribonucleotide reductase (6), whereas the EA-D component BMRF1 (p54) is related to an EBV-specific DNA polymerase (14). The 
recombinant p54 used in this investigation comprises the complete amino acid sequence specified by BMRF1. Like p138, this antigen had excellent reactivities (IgM and IgG) with most of the sera from patients with IM together with high diagnostic significance; i.e., none of the ABDs proved to be IgM positive. High levels of anti-p54-IgG in sera from patients with IM have been observed earlier by a similar recombinant ELISA (7). The diagnostic significance of p138 and p54 has also been substantiated previously in Western blot experiments with recombinant and natural antigens and a panel of sera from patients with IM (15).

Although p150 (BcLF1) is the major viral capsid component, gp125 (BALF4) seems to form the dominant antigen of the VCA complex in current assay systems (19). Our data show that testing for IgM antibodies with the recombinant p150 ELISA may support the diagnosis of IM. However, despite high concentrations of $\mathrm{p} 150$ in the coating solution, reactions were usually weak. Moreover, no correlation was found between p150-IgG and results of standard VCA-IgG testing.

Because intact p150 obtained from virus-producing cells, likewise, showed a restricted seroreactivity, one must assume that other highly sensitive and, perhaps, conformational epitopes are the diagnostically relevant epitopes on native p150 or that other components of the VCA complex are essential for serodiagnosis.

Excellent sensitivity and high diagnostic significance were obtained with the EBNA-1 (BKRF1)-specific p72-IgG assay. Considering the low antigen concentration used in the assay (Table 1) and taking into account the strong reactivities of sera from individuals with past EBV infections, this antigen is the most reactive one among the recombinant EBV antigens that we studied. It must be emphasized, however, that the sensitivity, and, hence, the diagnostic significance of the p72-ELISA, depends entirely on the antigen concentration that is used for coating. From ELISA series with increased concentrations of p72, as well as from Western and dot blot assays, it became evident that conditions can be established that reveal EBNA-1-IgM antibodies in almost all serum specimens from patients with IM (data not shown). The antigen concentration selected for use in this study was suitable for the assay of IgG antibodies with regard to differentiation between early and past infections. This is facilitated by the well-known delayed appearance of EBNA1-IgG in the course of a primary EBV infection (9). The strong reactivity of the p72-IgG that we observed by ELISA was in full agreement with those in earlier studies of the highly immunogenic properties of the carboxy-terminal domain of p72. On this basis, an ELISA method has been developed which proved to be 100 -fold more sensitive than ACIF (17).

A further advantage of the recombinant p72 might arise from deletion of the Gly-Ala copolymer from its amino acid sequence. This structural part of EBNA-1 was shown to react with rheumatoid antibodies as well as with autoantibodies in sera from patients with $\operatorname{IM}(21,23)$. Furthermore, it has been suggested that the Gly-Ala copolymer of EBNA-1, together with cellular proteins with similar structures, are the target for anti-rheumatoid arthritis nuclear antigen antibodies (23). In view of the results presented in those reports, we assume that omission of the putative cross-reacting epitopes in the amino-terminal half of p72 added substantially to the specificity of our test system.

On the basis of the results of this study, the following conclusions can be drawn. The most useful markers in the diagnosis of IM caused by EBV are IgM antibodies p54,
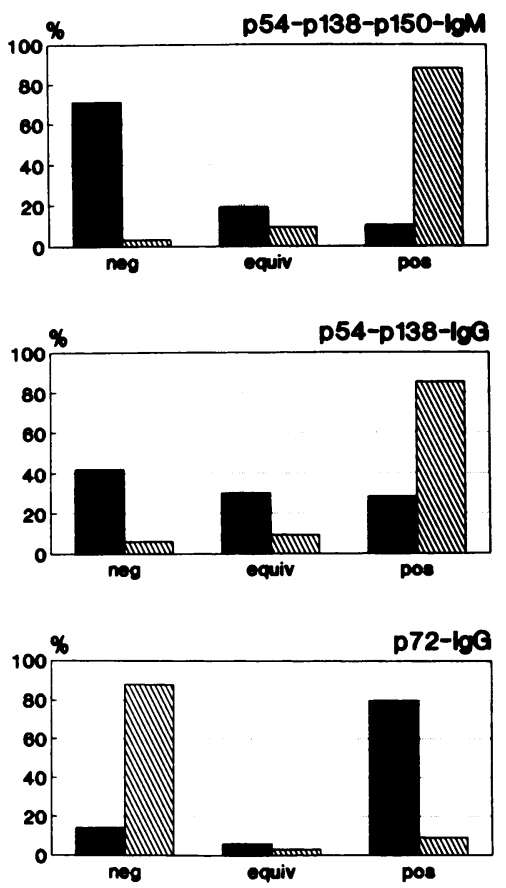

FIG. 2. Hypothetical combination of antigens by reevaluation of the results presented in Fig. 1 for a set of three hypothetical ELISAs combining IgM antibodies to p54, p138, and p150; IgG antibodies to p54 and p138; as well as IgG antibodies to p72. Sera were from ABDs $(\square)$ and patients with IM ( $\mathbb{Q})$. See legend to Fig. 1 for definitions of neg, equiv, and pos.

$\mathrm{p} 138$, and p150. Additional positive markers for recent or ongoing IM can be IgG antibodies to p54 and p138. Antip72-IgG is typically negative in the early phase of EBV infections. If it is positive, however, it is a potent indicator of past exposure to the virus. Judged on this basis, the ELISA results led to a laboratory diagnosis for the individual serum specimens from patients with IM which proved to be comparable to or even better than the diagnosis we obtained by standard IF and IP EBV serology (see column labeled $R$ in Table 2).

Despite their obvious discriminative diagnostic powers, the multiple individual ELISAs, in their present form, are not suited for routine laboratory diagnosis of EBV infections. In agreement with the conclusions presented above, however, it seems to be possible to reduce the number of necessary tests per serum specimen by assaying simultaneously for anti-p54-, anti-p138, and anti-p150-IgM, by combining p54 and p138 in a second assay for IgG antibodies, and, finally, by testing for anti-p72-IgG. When the results shown in Fig. 1 were reevaluated by using the aforementioned hypothetical combination of antigens, the data presented in Fig. 2 evolved. It is highly suggestive of the possibility that a rapid, reliable, and discriminative ELISA system can be established for the specific diagnosis of acute EBV infection and will be tested under routine conditions in the near future.

\section{LITERATURE CITED}

1. Angel, F., G. Decaussin, J. Daillie, and T. Ooka. 1987. Comparison of early polypeptides induced in EBV producer and nonproducer lymphoid cell lines. Ann. Inst. Pasteur Virol. 138:169181.

2. Cheeseman, S. H. 1988. Infectious mononucleosis. Semin. He- 
matol. 25:261-268

3. Evans, A. S., J. C. Niedermann, L. C. Cenabre, B. West, and B. A. Richards. 1975. A prospective evaluation of heterophile and Epstein-Barr virus-specific IgM antibody tests in clinical and subclinical infectious mononucleosis. Specificity and sensitivity of the tests and persistence of antibody. J. Infect. Dis. 132:546-553.

4. Fox, R. I., S. Scott, R. Houghten, A. Whalley, J. Geltofsky, J. Vaughan, and R. Smith. 1987. Synthetic peptide derived from the Epstein-Barr virus encoded early diffuse antigen (EA-D) reactive with human antibodies. J. Clin. Lab. Anal. 1:140-145.

5. Geltofsky, J. E., R. S. Smith, A. Whalley, and G. Rhodes. 1987. Use of a synthetic peptide-based ELISA for the diagnosis of infectious mononucleosis and other diseases. J. Clin. Lab. Anal. 1:153-162.

6. Goldschmidts, W. L., M. Ginsburg, and G. R. Pearson. 1989. Neutralization of Epstein-Barr virus-induced ribonucleotide reductase with antibody to the major restricted early antigen polypeptide. Virology 170:330-333.

7. Halprin, J., A. L. Scott, L. Jacobsen, P. H. Levine, J. H. C. Ho, J. C. Niederman, S. D. Hayward, and G. Milman. 1986. Enzyme-linked immunosorbent assay of antibodies to EpsteinBarr virus nuclear and early antigen in patients with infectious mononucleosis and nasopharyngeal carcinoma. Ann. Intern. Med. 104:331-337.

8. Henle, G., E. T. Lenette, M. A. Alspaugh, and W. Henle. 1979. Rheumatoid factor as a cause of positive reactions in tests for Epstein-Barr virus-specific IgM antibodies. Clin. Exp. Immunol. 36:415-422.

9. Henle, W., G. Henle, J. Andersson, J. Ernberg, G. Klein, C. A. Horwitz, G. Marklund, L. Rymo, C. Wellinder, and S. E. Straus. 1987. Antibody responses to Epstein-Barr virus-determined nuclear antigen (EBNA)-1 and EBNA-2 in acute and chronic Epstein-Barr virus infection. Proc. Natl. Acad. Sci. USA 84: 570-574.

10. Henle, W., G. Henle, and C. A. Horwitz. 1974. Epstein-Barr virus specific diagnostic tests in infectious mononucleosis. Hum. Pathol. 5:551-565.

11. Hinderer, W., H. Nebel-Schickel, H.-H. Sonneborn, M. Motz, R. Kühbeck, and H. Wolf. 1988. Purification of four different recombinant EBV-antigens synthesized in E. coli and their diagnostic application. J. Exp. Clin. Cancer Res. 7(Suppl.):132.

12. Kyhse-Andersen, J. 1984. Electroblotting of multiple gels: a simple apparatus without buffer tank for rapid transfer of proteins from polyacrylamide to nitrocellulose. J. Biochem. Biophys. Methods 10:203-209.

13. Laemmli, U. K. 1970 . Cleavage of structural proteins during the assembly of the head of bacteriophage T4. Nature (London)
227:680-685.

14. Li, J.-S., B.-S. Zhou, G. E. Dutchman, S. P. Grill, R.-S. Tan, and Y.-C. Cheng. 1987. Association of Epstein-Barr virus early antigen diffuse component and virus-specified DNA polymerase activity. J. Virol. 61:2947-2949.

15. Middeldorp, J. M., and P. Herbrink. 1988. Epstein-Barr virus specific marker molecules for early diagnosis of infectious mononucleosis. J. Virol. Methods 21:133-146.

16. Middeldorp, J. M., and R. H. Meloen. 1988. Epitope-mapping on the Epstein-Barr virus major capsid protein using systematic synthesis of overlapping oligopeptides. J. Virol. Methods 21: 147-159.

17. Milman, G., A. L. Scott, M.-S. Cho, S. C. Hartmann, D. K. Ades, G. S. Hayward, P.-F. Ki, J. T. August, and S. D. Hayward. 1985. Carboxy-terminal domain of the Epstein-Barr virus nuclear antigen is highly immunogenic in man. Proc. Natl. Acad. Sci. USA 82:6300-6304.

18. Motz, M., J. Fan, R. Seibl, W. Jilg, and H. Wolf. 1986 Expression of the Epstein-Barr virus $138 \mathrm{kDa}$ early protein in Escherichia coli for the use as antigen in diagnostic tests. Gene 42:303-312.

19. Pearson, G. R. 1988. ELISA tests and monoclonal antibodies for EBV. J. Virol. Methods 21:97-104.

20. Reedman, B. M., and G. Klein. 1973. Cellular localization of an Epstein-Barr virus (EBV)-associated complement-fixing antigen in producer and nonproducer lymphoblastoid cell lines. Int. J. Cancer 11:499-520.

21. Rhodes, G., H. Rumpold, P. Kurki, K. M. Pattrick, D. A. Carson, and J. H. Vaughan. 1987. Autoantibodies in infectious mononucleosis have specificity for the glycine-alanine repeating region of the Epstein-Barr virus nuclear antigen. J. Exp. Med. 165:1026-1040.

22. Sumaya, C. V., and Y. Ench. 1985. Epstein-Barr virus infectious mononucleosis in children. II. Heterophil antibody and viralspecific responses. Pediatrics 75:1011-1019.

23. Venables, P. J. W., T. Pawlowski, P. A. Mumford, C. Brown, D.H. Crawford, and R. N. Maini. 1988. Reaction of antibodies to rheumatoid arthritis nuclear antigen with a synthetic peptide corresponding to part of Epstein-Barr nuclear antigen 1. Ann. Rheum. Dis. 47:270-279.

24. Wolf, H., M. Motz, R. Kühbeck, R. Seibl, G. J. Bayliss, S. Modrow, and J. Fan. 1985. Selection and production by genetechnological methods of medically relevant EBV-related antigens, p. 485-494. In P. H. Levine, D. V. Ablashi, and G. R. Pearson (ed.), Developments in medical virology, vol. 1, Epstein-Barr virus and associated diseases. M. Nijhoff Publishing, Boston. 